\begin{abstract}
Nako Stefanov
Doktor filozofskih i istorijskih nauka

Sofijski univerzitet 'Sv. Kliment Ohridski', Fakultet klasične i savremene filologije, Centar za istočne jezike i kulture, Katedra za istočnoazijske jezike i kulture
\end{abstract}

\title{
Projekat „Pojas i put” kao geostrateška revolucija i format "16+1" - problemi i perspektive
}

\begin{abstract}
Sažetak
Postavljanje temelja održivog razvoja postaje ključno pitanje za celokupno čovečanstvo usled savremenih previranja. Projekat „Pojas i put” je deo tih temelja, koji $\mathrm{u}$ isto vreme poprima karakter geostrateške revolucije $\mathrm{u}$ različitim dimenzijama: - preraspodeljivanju ravnoteže na globalnom nivou u smeru nastajanja multipolarnog sveta; • menjanju društveno-ekonomske dinamike zemalja koje učestvuju u projektu na platformi win-win razvoja; • predlaganju alternative trenutno dominantnom neoliberalnom modelu i svim njegovim različitim aspektima. Ovaj izveštaj ima za cilj (1) da ispita važne aspekte celokupnog projekta „Pojas i put”; (2) da analizira komponentu ovog projekta nazvanu format "16+1"; (3) da dâ pregled problema i perspektiva projekta "Pojas i put” i formata „16+1".

Ključne reči:

Inicijativa „Pojas i put”, format „16+1”, geostrateška revolucija, multipolarni svet, win-win razvoj, alternativa neoliberalnom modelu
\end{abstract}

\section{UVOD}

Na zalasku druge decenije XXI veka, u svetu se intenziviraju društvene, ekonomske, političke i tehnološke promene koje karakteriše neravnoteža, odnosno produbljivanje nelinearne, turbulentne dinamike. Postalo je nemoguće predvideti kakva je dugoročna ili čak srednjoročna perspektiva na globalnom, nacionalnom, pa i lokalnom nivou. 
Ova situacija se dobro može opisati izrazom „singularitet”. Doba „singulariteta" je doba u kome prethodni modeli i pojmovi više nisu primenljivi, kada nastupa nešto novo, za šta se još uvek ne zna kako će funkcionisati. Jedan od ključnih razloga za nastupanje doba „singulariteta” je kriza industrijsko-tehnološkog načina proizvodnje, tj. industrijalizma ili „industrijske civilizacije". Suočavamo se sa prestankom mogućnosti za ekstenzivan razvoj zbog ograničenja koja postavlja životna sredina, odnosno ograničenost neobnovljivih izvora energije.

Tehnološka osnova, koja je do danas izgrađena, i energetski potencijal, koji je čovečanstvo na toj osnovi korak po korak stvorilo, stavlja tačku na postojeće modele ekstenzivnog rasta. S druge strane, taj tehnološki kompleks stvara uslove za osmišljavanje novih tehnoloških platformi, koje su društveno i ekološki mnogo prihvatljivije.

Drugim rečima, već stvoreni tehnološki uslovi postepeno vode čovečanstvo ka novoj proizvodno-tehnološkoj i društveno-ekonomskoj paradigmi. Ipak, sistemska kriza neoliberalnog kapitalizma otežava uvođenje novog društveno-tehnološkog modela. Glavni uzrok toga je upravo ova sistemska kriza, koja stvara mnoge nepredviđene pretnje.

U uslovima sve većih previranja i haosa na globalnom nivou, postavljanje temelja održivog razvoja postaje ključno pitanje za celokupno čovečanstvo. U tom haosu, projekat „Pojas i put” poprima odlike geostrateške revolucije $u$ više dimenzija.

Opšte je poznato da se XIX vek naziva „vekom geopolitike”. XX vek se naziva "vekom geoekonomije". U tom smislu, možda se XXI vek može nazvati „vekom geokulture” ili „geofilozofije”. Drugim rečima, u XXI veku bi trebalo da se izgradi „svest da je postojanje čovečanstva geocentrično”. To znači da on mora da bude vek duhovnosti, a ne vek preteranog konzumerizma i hedonizma malog dela čovečanstva i obrnute situacije za većinu čovečanstva. Posmatrano iz ovog ugla, može se reći da projekat „Pojas i put” može i mora da ima ulogu geostrateške revolucije, te da stoga treba da se nazove geostrateškim projektom.

Ovaj izveštaj ima za cilj:

- da ispita neke od važnih aspekata celokupnog projekta „Pojas i put";

- da analizira jednu, nipošto manje važnu komponentu ovog projekta - takozvani format „16+1”;

- da ispita probleme i perspektive projekta „Pojas i put”, ali i formata "16+1". 
Cilj izveštaja postiže se kroz sledeće glavne zadatke, koji su strukturisani kao glavni delovi izveštaja:

- Projekat „Pojas i put” kao geostrateška revolucija;

- Format „16+1" kao važan deo geostrateškog projekta „Pojas i put”;

- O problemima i perspektivama projekta „Pojas i put” i formata „16+1".

Osnovni metodološki pristupi korišćeni u izveštaju su:

- Sistemsko-strukturalni pristup, koji date entitete posmatra kao „sisteme", odnosno kao skupove međusobno povezanih delova koji čine celinu. Komponente sistema stoje u određenim odnosima, tj. strukturisani su;

- Istorijski pristup - pojave, bilo da su prirodne ili društvene, ne mogu se u potpunosti razumeti ukoliko se ne uzme u obzir njihov razvoj kroz vreme;

- Geopolitičke i geoekonomske platforme - ove platforme ispituju sveukupan politički i ekonomski razvoj određene društvene pojave tako što uzimaju u obzir geografske i prirodne činioce koji upravljaju datom pojavom i njenom interakcijom.

\section{PROJEKAT „POJAS I PUT” KAO GEOSTRATEŠKA REVOLUCIJA}

Projekat „Pojas i put” je pokazatelj povećanog geopolitičkog i geostrateškog potencijala Narodne Republike Kine (NRK) i novog geostrateškog načina razmišljanja lidera Kine, potpomognutog instrumentima „meke moći”, odnosno ekonomskim uticajem i odnosima.

Istorijski posmatrano, Kina je jedna od najstarijih civilizacija sa održivom etatističkom tradicijom. Iako Kina ima značajan pristup Svetskom moru, ona se u geopolitičkom smislu bez sumnje pokazala kao sila koja pripada „kopnenim civilizacijama”, takozvanim telurokratijama. 


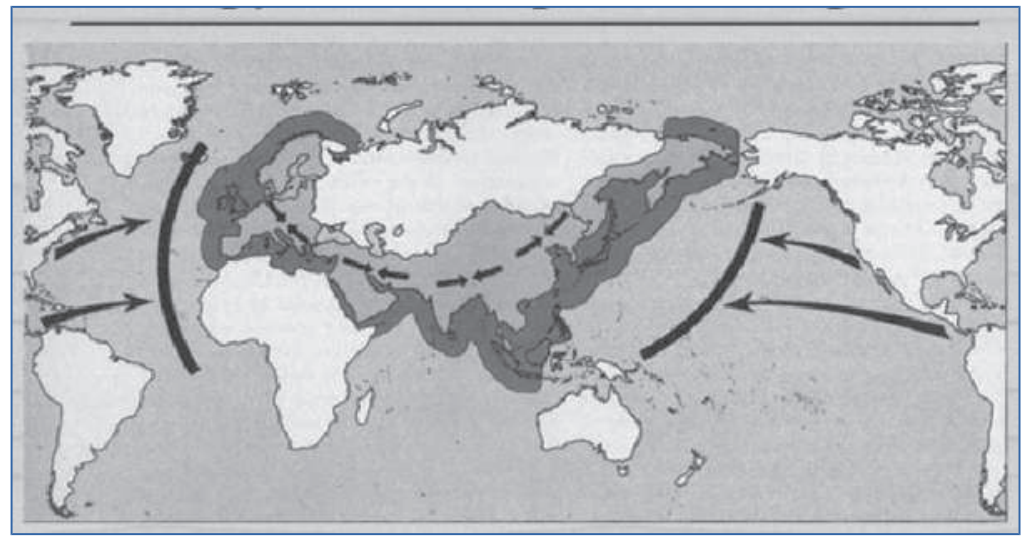

Dominacija pomorskih sila: sistem britanske imperije zasnivao se na opkoljavanju evroazijskog kontinenta pomorskim putem. Ova dominacija se ostvarivala kroz premoć na pomorskom putu koji prati obode ovog kontinenta. ${ }^{1}$

Prema klasičnom geopolitičkom shvatanju sveta, postoji presudan sukob između pomorskih sila, s jedne, i kopnenih sila, s druge strane. Treba napomenuti da su do sada pomorske sile bile te koje su na različite načine dominirale istorijskim vremenom i prostorom. Kopnene sile su morale da se brane, odnosno bile su u odbrambenom položaju.

Na dominaciju i napadačku, agresivnu strategiju „mora”, tj. pomorskih država ukazuje i pojam svetskih središta, odnosno onih prostora unutar kojih se odigrava znatan deo ekonomskog, političkog, tehnološkog i kulturnog života čovečanstva:

- U antičko doba i u srednjem veku ulogu središta imalo je Sredozemno more, gde je dominantna pomorska sila najpre bilo Rimsko carstvo, a zatim Mletačka republika. Mletačka republika je uspešno manevrisala zemljama i teritorijama, materijalnim dobrima i finansijskim tokovima, kao i poduhvatima poput krstaških. Mletačka republika kao dominantna sila bila je jasan odraz nadmoći mora nad kopnom. Ne smemo da zaboravimo da je Britanija bila mletački projekat, baš kao i Britanska istočnoindijska kompanija - jedinstven entitet koji je imao svoju vojsku i mornaricu, tajnu službu i diplomatiju. Ona je obezbedila uspeh britanskih kolonijalnih osvajanja u Indiji, označivši početak velikog britanskog kolonijalnog carstva. Ova kompanija je de facto nastala spajanjem dve prvobitno mletačke kompanije. Upravnik Istočnoindijske kompanije, Tomas Smit, diplomirao je na Univerzitetu u Padovi, jednom od središta mletačkog uticaja;

\footnotetext{
$1 \mathrm{http}: / /$ policytensor.com/category/geopolitics/
} 
- U moderno doba, Atlantski okean postao je novo središte, a dominantne pomorske sile bile su najpre Britanija, a nakon II svetskog rata - Sjedinjene Države.

- Doskora su postojala predviđanja da će u XXI veku Tihi okean postati središte sveta. Prema ovim predviđanjima, pomorske zemlje poput SAD i Japana morale bi biti dominantne sile novog veka.

Projekat „Pojas i put” menja geopolitičku i geoekonomsku ravnotežu u korist evroazijskog kontinenta. Ako se realizuje ovaj projekat, Evroazija će postati središte sveta umesto Tihog okeana. Drugim rečima, zahvaljujući ovom projektu uspostaviće se sistem uzajamno korisnih odnosa, aktivni društveno-ekonomski, tehnički i kulturni život, a dominantne sile biće kopnene sile - Kina, Rusija, Iran...

Projekat „Pojas i put” se stoga može nazvati geostrateškom revolucijom jer, ukoliko bude realizovan, ima potencijal da promeni globalnu ravnotežu od dosadašnjeg jednopolarnog sveta u kojem dominira jedna zemlja - SAD - do multipolarnog sveta u kome se odvija interakcija više sila.

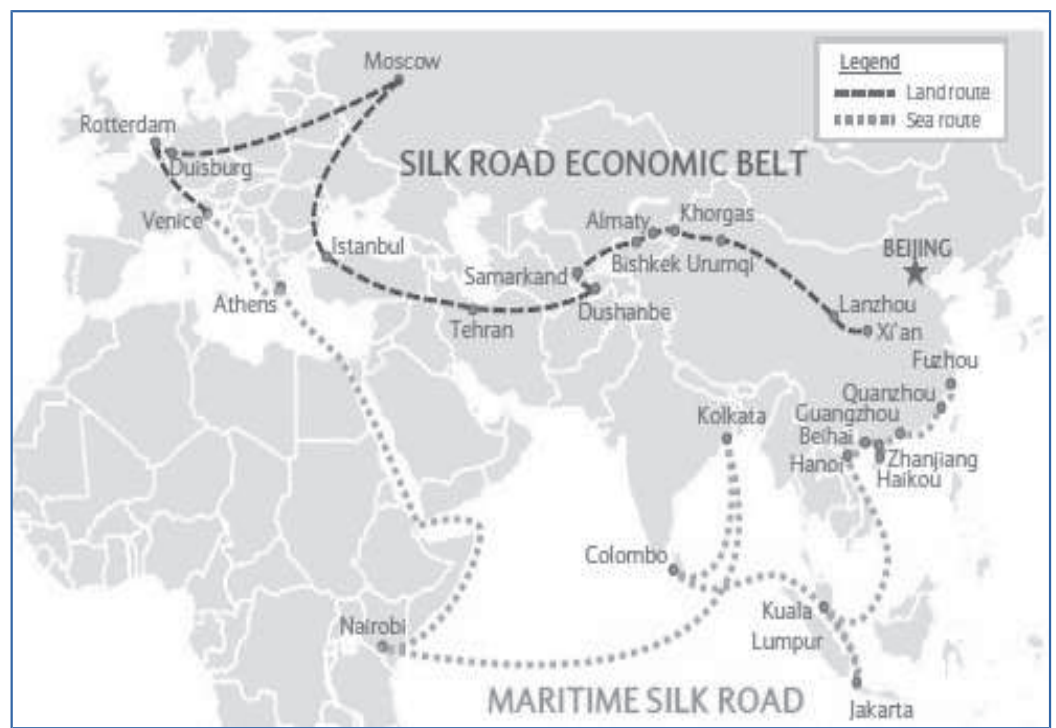

Realizacija projekta „Pojas i put” je fundamentalna geopolitička i geoekonomska promena, globalna transformacija džinovskih razmera, koju možemo nazvati geostrateškom revolucijom. 


\section{FORMAT „16+1” KAO VAŽAN DEO GEOSTRATEŠKOG PROJEKTA „POJAS I PUT”}

Kina je 2011. godine predložila zemljama Srednje i Istočne Evrope regionalnu saradnju prema formatu "16+1". Ova inicijativa Narodne Republike Kine usmerena je ka jačanju i proširenju saradnje sa jedanaest članica EU i pet balkanskih zemalja - Albanijom, Bosnom i Hercegovinom, Bugarskom, Hrvatskom, Češkom, Estonijom, Mađarskom, Letonijom, Litvanijom, Makedonijom, Crnom Gorom, Poljskom, Rumunijom, Srbijom, Slovačkom i Slovenijom - u oblasti ulaganja, saobraćaja, finansija, nauke, obrazovanja i kulture. U okviru inicijative, Kina je definisala tri potencijalne prioritetne oblasti ekonomske saradnje: infrastrukturu, visoku tehnologiju i ekološke tehnologije. Kineski analitičari navode dva glavna razloga za ovu odluku Pekinga:

- Sve veću važnost zemalja ove regije unutar Evropske unije;

- Delimično pomirenje ideoloških neslaganja koja su otežavala saradnju prethodnih godina. S druge strane, kriza evrozone može biti razlog što su zemlje Srednje i Istočne Evrope pokazale zainteresovanost za razvoj saradnje sa Kinom.

Odnosi sa zemljama Srednje i Istočne Evrope dugo nisu smatrani prioritetom u spoljnoj politici NRK. Nakon raspada SSSR-a i Saveta za uzajamnu ekonomsku pomoć (SEV), bivše socijalističke zemlje su preusmerile politiku ka integraciji u institucije Zapada. Shodno tome, one su zapostavile veze sa Kinom.

Format' $16+1$ '

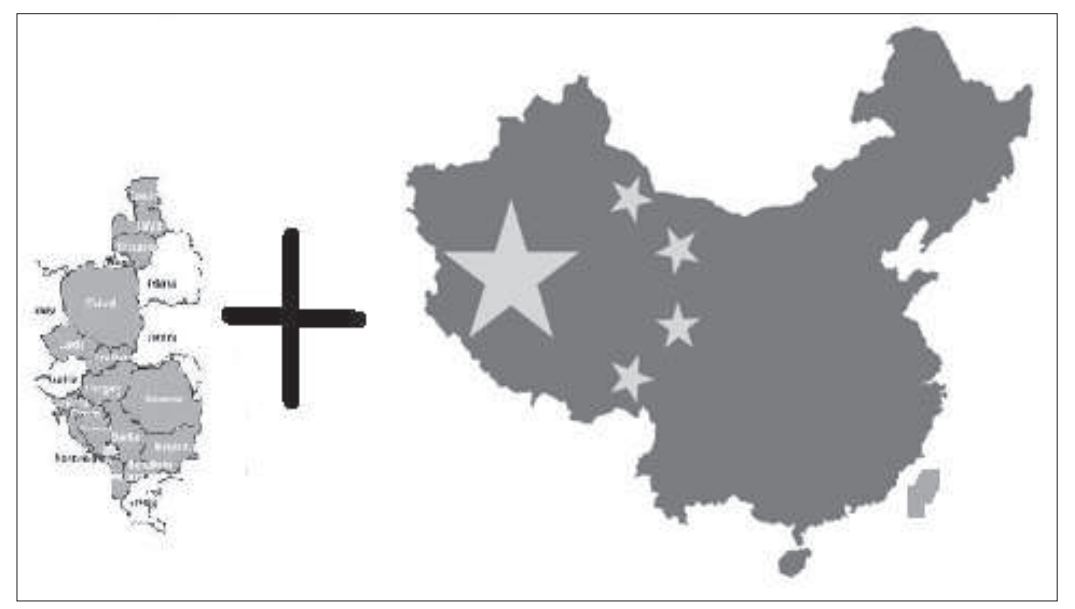


Kina je 2011. godine obnovila saradnju sa ovom grupom zemalja kao celinom. Nakon što je pokrenuta kineska inicijativa, iste godine je organizovan i Ekonomski forum u Budimpešti (Mađarska). Godinu dana kasnije, 2012. godine, zvanično je otpočelo primenjivanje formule „16+1" u Varšavi (Poljska), gde je održan prvi sastanak na nivou šefova vlada. Kasnije runde sastanaka premijera država na visokom nivou održane su u Bukureštu (Rumunija, 2013), Beogradu (Srbija, 2014) i Sudžou (Kina, 2015).

Letonija je 2016. godine organizovala ključni događaj za saradnju između srednjoevropskih i istočnoevropskih zemalja i Kine („16+1”) - sastanak šefova vlada (samit).

Treba napomenuti da su, osim ovih samita, održani i brojni događaji sekundarne važnosti. Na primer, pokrenute su razne inicijative, uključujući i forume usmerene ka ekonomiji, investicijama i saradnji. Takve konferencije, seminari i slični događaji posvećeni su temama poput turizma, obrazovanja, poljoprivrede, energetike i pitanjima razvoja infrastrukture.

Svedoci smo nesumnjivog napretka $u$ institucionalizaciji formata "16+1". 2012. godine osnovan je stalni sekretarijat Ministarstva spoljnih poslova Kine vezan za format „16+1”. U Varšavi je 2014. godine formiran Stalni sekretarijat za podsticanje investicija. Postoji i nekoliko udruženja i organizacija čiji su koordinatori pojedinačne zemlje (na primer, poljoprivredna saradnja, čiji je koordinator Bugarska, i železnice, čiji je koordinator Srbija).

Iako na samom početku format "16+1" nije smatran važnom inicijativom sa geopolitičkog, pa čak ni ekonomskog stanovišta, on je u pozadini nekoliko ključnih događaja i procesa počeo da poprima odlike geostrateškog plana. Ti ključni događaji i procesi su:

- Prvi događaj je nesumnjivo projekat „Pojas i put”, koji je pokrenuo predsednik NRK Si Đinping, a koji sam po sebi predstavlja inicijativu svetskog značaja. Taj projekat povećava važnost zemalja Srednje i Istočne Evrope;

- Drugi proces je svakako „evropska kriza”, koja se ispoljila na različite načine - kao „odjeci” globalne krize koja je počela 2008. godine, dužnički problemi u evrozoni, uključujući i „slučaj Grčke”, i kao „žarišta”, u slučaju Ukrajine, sankcija uvedenim Rusiji, takozvane „migrantske krize" i tako dalje.

Zbog svega toga su zemlje Srednje i Istočne Evrope počele da traže drugi izvor ekonomske stabilnosti, van EU, SAD ili Ruske Federacije. Aktivna saradnja sa NRK, posebno u vezi sa projektom „Pojas i put”, vremenom je za zemlje Srednje i Istočne Evrope postala važan instrument, koji nesumnjivo daje novi značaj ovoj grupi zemalja koje su do sada smatrane periferijom 
EU ili tampon-zonom između EU i Ruske Federacije. Zahvaljujući pomenutom projektu i formatu „16+1", počele su da se otvaraju mogućnosti da ove zemlje dobiju mnogo značajniju ulogu u nekoliko oblasti i da daju novi smisao međunarodnoj saradnji na globalnom nivou i to:

- u oblasti odnosa EU i NRK, jer će, u slučaju da se realizuje projekat „Pojas i put”, zemlje Srednje i Istočne Evrope biti spona, a ne periferija;

- u međunarodnoj saradnji, gde projekat „Pojas i put” postaje najveća inicijativa na svetu, a zemlje Srednje i Istočne Evrope postaju značajna komponenta u ovom geostrateškom projektu sa globalnom perspektivom.

\section{O PROBLEMIMA I PERSPEKTIVAMA PROJEKTA „POJAS I PUT” I FORMATA „16+1”}

Kada govorimo o formatu „16+1”, posebno u kontekstu projekta „Pojas i put", ne smemo da prenebregnemo da ne postoje samo perspektive, već i problemi. Na primer, vredi dati pregled nekoliko mišljenja vodećih trustova mozgova i mas-medija.

Neki autori komentarišu: „Pola decenije nakon što je mreža saradnje između Kine i šesnaest zemalja Srednje i Istočne Evrope pokrenuta, njeni ekonomski i politički rezultati su za sada nejednako raspodeljeni". ${ }^{2}$

U ovom članku su citirana mišljenja, poput stava Petra Kratočvila, direktora praškog Instituta za međunarodne odnose, da „[t]o nije zaista multilateralan format - više je u pitanju grupa zemalja sa kojima je Kina odabrala da uspostavi bilateralne odnose. Kad su u pitanju investicije, to su uglavnom Poljska i Mađarska, a kad su u pitanju projekti izgradnje, to su Rumunija i Srbija". ${ }^{3}$

U istom članku drugi stručnjak, Anastas Vangeli, sa Poljske akademije nauka, kaže da su „Južna i Istočna Evropa pre poligon za „Pojas i put””, da je to više „eksperiment” nego „plan Kine” i da Peking pokušava „da vidi da li će im ova vrsta diplomatije pomoći da poboljšaju ekonomske odnose". ${ }^{4}$

Agata Krac iz Evropskog saveta za spoljne odnose, trusta mozgova sa sedištem u Londonu, smatra da je „prvobitna ideja bila da se zemlje Srednje i Istočne Evrope tretiraju kao Azija i Afrika”. „To je bio veliki šok - oni su

\footnotetext{
2 Eric Maurice. China's 16+1 foray into Central and Eastern Europe; https://euobserver. com/eu-china/138347

3 Ibidem.

4 Ibidem.
} 
objasnili da neće biti zajmova za projekte koje će Kina izgraditi." Za Krac, „uspeh inicijative '16+1' je politički, a ne ekonomski". ${ }^{5}$

Ideja da postoje ograničenja u saradnji srednjoevropskih i istočnoevropskih zemalja i NRK izneta je i u članku Ričarda Turčanjija, zamenika direktora slovačkog Instituta za azijske studije (CENAA), koji kaže da „spisak ekonomskih uspeha - glavnog motiva za učestvovanje u platformi '16+1', barem kad su u pitanju zemlje Srednje i Istočne Evrope - nije tako impresivan". ${ }^{6}$ On takođe zaključuje: „Kada je pokrenuta platforma '16+1', šesnaest zemalja Srednje i Istočne Evrope je imalo nerealna očekivanja od saradnje sa Kinom - i vrlo je verovatno da su do sada shvatile kako stoje stvari. Danas se situacija možda preokrenula, pa Kina ima nerealna očekivanja oko toga šta može da postigne u ovim zemljama i kako se platforma '16+1' može iskoristiti". ${ }^{7}$

Tu su i druga mišljenja, poput stava Kerija Brauna, koji kaže: „Svi su do sada upoznati sa željom Kine da tokom proteklih nekoliko godina oformi sopstvenu međunarodnu mrežu multilateralnih grupacija. [...] '16+1' je samo najzapadnija od tih grupacija. Kada je ideja prvi put predstavljena, otprilike u vreme kada je kineski predsednik Si Đinping postao generalni sekretar Komunističke partije 2012. godine, EU ju je dočekala sa podozrenjem". 8

Nakon toga, Braun iznosi neke geopolitičke spekulacije: „Inicijativa 'Pojas i put', koja formira komfornu, nekonfliktnu zonu kineskog interesa Rusiji ispred nosa, sve više deluje kao vrhunski diplomatski potez Kine. Duž ogromnog pojasa u Srednjoj Aziji se povećavaju kineska ulaganja i otopljavaju političke veze sa Pekingom, umesto Moskvom. „16+1" nudi vrlo sličan scenario. Mnoge članice su bivše satelitske države Sovjetskog Saveza; one prirodno potpadaju pod sferu interesa i uticaja Rusije. Ipak, Kina po prvi put gradi benignu bambusovu zavesu oko Rusije tamo gde je, pre više decenija, bila gvozdena zavesa za vreme Sovjetskog Saveza. Uz to, baš kao i u Srednjoj Aziji, sve što Rusija može da uradi je da se ljubazno smeška i trpi tu novinu". ${ }^{9}$

Na kraju, Braun zaključuje: „Optimizma ne manjka; samiti „16+1” su popularni. Problem je, međutim, kao i drugde, to što postoje najrazličitija očekivanja od Kine, ali što su razočaranja često međusobno zaprepašćujuće

$5 \quad$ Eric Maurice. China's 16+1 foray into Central and Eastern Europe; https://euobserver. com/eu-china/138347

$6 \quad$ Richard Q. Turcsányi. The Limits of China's Cooperation with Central and Eastern Europe. https://thediplomat.com/2015/12/the-limits-of-chinas-cooperation-with-centraland-eastern-europe/

7 Ibidem.

8 Kerry Brown, China's Geopolitical Aims: The Curious Case of the 16-Plus-1; https://thediplomat.com/2017/05/chinas-geopolitical-aims-the-curious-case-of-the-16-plus-1/

$9 \quad$ Ibidem. 
slična. Za Kinu će biti veoma važno da ispuni barem nešto od onoga što se od nje očekuje". ${ }^{10}$

Takvi stavovi su jasan pokazatelj da, premda prilike koje nudi format „16+1" unutar projekta „Pojas i put” pružaju mogućnosti na osnovu formule za uzajamno koristan razvoj, one nisu izložene samo finansijskim, ekonomskim i tehničkim problemima uobičajenim za tako ogroman projekat. Nesumnjivo za njih postoje i političke i ideološke prepreke.

Kako pokazuju navedena mišljenja, u zemljama formata "16+1" postoje jasno orijentisani krugovi, ali pre svega podrška za ove krugove koja dolazi od spolja, od određenih sila sa Zapada. One teže ka tome da javnost formira negativno mišljenje kako o uzajamno korisnoj saradnji sa NRK u okviru formata „16+1” tako i o realizaciji projekta „Pojas i put”. Moguće je da takve tendencije mogu veoma negativno da se odraze i na format "16+1" i na realizaciju projekta „Pojas i put”.

\section{UMESTO ZAKLJUČKA}

Sve što je do sada navedeno treba uzeti u obzir kad je u pitanju potreba za uspešnim razvojem uzajamno korisne saradnje. To podrazumeva ulaganje neophodnih napora da se šira javnost zemalja Srednje i Istočne Evrope upozna sa formatom "16+1" i projektom „Pojas i put”.

$\mathrm{Za}$ to je potrebno ne samo razvijanje finansijsko-ekonomske i tehničke saradnje, već i posvećivanje pažnje široj kulturnoj, naučnoj i drugim vrstama saradnje. Da bi se stvorile prilike za takozvanu „narodnu diplomatiju", uključujući i regionalnu saradnju između gradova i sela, neophodno je obratiti pažnju ne samo na ostvarenje takve saradnje preko zvaničnih kanala, već i preko nevladinih organizacija. Gde je izvodljivo, to treba da se dogodi ne samo bilateralno, već na multilateralnoj osnovi, jer je takav slučaj sa formatom "16+1".

U tom smislu, potrebna je sveobuhvatna strategija za učešće šire javnosti kao jedna od garancija za uspeh međusobno korisne saradnje i, pre svega, međusobno korisnog razvoja u okviru formata "16+1” i projekta „Pojas i put".

\footnotetext{
10 Kerry Brown, China's Geopolitical Aims: The Curious Case of the 16-Plus-1; https://the-
} diplomat.com/2017/05/chinas-geopolitical-aims-the-curious-case-of-the-16-plus-1/ 


\section{IZVORI}

1. http://policytensor.com/category/geopolitics/

2. Eric Maurice. China's 16+1 foray into Central and Eastern Europe; https://euobserver.com/eu-china/138347

3. Richard Q. Turcsányi. The Limits of China's Cooperation With Central and Eastern Europe; https://thediplomat.com/2015/12/the-limits-of-chinas-cooperation-with-central-and-eastern-europe/

4. Kerry Brown, China's Geopolitical Aims: The Curious Case of the 16-Plus-1; https://thediplomat.com/2017/05/chinas-geopolitical-aims-the-curious-caseof-the-16-plus-1/.

Prevod sa engleskog jezika:

Jelena Bošnjak 